\title{
Myb and NF-M: combinatorial activators of myeloid genes in heterologous cell types
}

\author{
Scott A. Ness, ${ }^{1}$ Elisabeth Kowenz-Leutz, Tullia Casini, ${ }^{2}$ Thomas Graf, ${ }^{2}$ and Achim Leutz \\ Zentrum für Molekulare Biologie, Universität Heidelberg (ZMBH), D-6900 Heidelberg 1, Germany; ${ }^{1}$ Department of \\ Biochemistry, Molecular Biology and Cell Biology, Northwestern University, Evanston, Illinois 60208-3500 USA; \\ ${ }^{2}$ Differentiation Programme, European Molecular Biology Laboratory, D-6900 Heidelberg 1, Germany
}

The c-Myb transcription factor regulates the differentiation of immature erythroid, lymphoid, and myeloid cells, although only the latter cells become transformed by the v-myb oncogene. These are also the only cells that express the Myb-regulated gene mim-1, suggesting that Myb requires tissue-specific, cooperating factors to activate such genes. Here, we investigated the tissue-specific regulation of the mim-1 promoter and found that it not only contains binding sites for Myb but also for NF-M, a myeloid-specific transcription factor that probably corresponds to mammalian C/EBP 3 . Both types of binding sites were found to be required for full activity of the promoter. Remarkably, ectopic coexpression of $M y b$ and NF-M proteins in erythroid cells or fibroblasts was sufficient to induce endogenous markers of myeloid differentiation, like the mim-1 and lysozyme genes. Our results indicate that $\mathrm{c}-\mathrm{Myb}$ and NF-M proteins act as a bipartite, combinatorial signal that regulates the expression of myeloid-specific genes, even in heterologous cell types.

[Key Words: Myb oncogene; C/EBP-like factors; hematopoiesis; transcription factors; gene expression]

Received February 10, 1993; revised version accepted March 4, 1993.

The v-myb oncogene was transduced independently by two retroviruses, avian myeloblastosis virus (AMV) and E26, both of which induce leukemias in animals and transform hematopoietic cells in tissue culture. The two forms of $\mathrm{v}-m y b$ are derived from a single proto-oncogene, c-myb (for review, see Lüscher and Eisenman 1990; Graf 1992), and several lines of evidence suggest that $\mathrm{v}-\mathrm{Myb}$ and $\mathrm{c}-\mathrm{Myb}$ proteins regulate hematopoietic cell differentiation. First, the viral, activated forms of $m y b$ transform immature myelomonocytic cells, that is, precursors of granulocytes and macrophages. Second, expression of the c-myb gene is high in immature myeloid, erythroid, and lymphoid cells and decreases as these cells differentiate (Gonda et al. 1982; Duprey and Boettiger 1985; Kastan et al. 1989). Third, ectopic expression of c-myb in immature erythroid cells has been shown to block their differentiation (Clarke et al. 1988; Todokoro et al. 1988; McClinton et al. 1990), and antisense oligonucleotides specific for c-myb block both the differentiation and the proliferation of hematopoietic cells in tissue culture (Gewirtz and Calabretta 1988; Gewirtz et al. 1989). Finally, transgenic mice with both copies of their c-myb gene disrupted are deficient for definitive hematopoiesis and die in utero (Mucenski et al. 1991).

The Myb products define a family of nuclear-localized, DNA-binding proteins, found in eukaryotic species from yeasts to mammals (Katzen et al. 1985; Paz-Ares et al. 1987; Tice-Baldwin et al. 1989). They share a unique
DNA-binding domain structure composed of two or three $\sim 52$-amino-acid-long homeo domain-like units (Kanei-Ishii et al. 1990; Saikumar et al. 1990; Frampton et al. 1991; Gabrielsen et al. 1991). In vertebrates, all of the Myb proteins recognize a common binding site and function as transcriptional activators (Boyle et al. 1984; Klempnauer et al. 1984; Biedenkapp et al. 1988; Ness et al. 1989; Nishina et al. 1989; Weston and Bishop 1989; Ibanez and Lipsick 1990; Kalkbrenner et al. 1990; Nakagoshi et al. 1990), suggesting that the oncogene transforms cells by altering the expression of specific target genes. The availability of a temperature-sensitive mutant of E26 virus (Beug et al. 1984) facilitated the identification of the first Myb-regulated gene, mim-1. The promoter of this gene contains three binding sites for $\mathrm{Myb}$, and its activity depends on the presence of active Myb proteins (Ness et al. 1989). Although the function of mim-1 remains unknown, it nevertheless provides a system in which to study how Myb proteins regulate the transcription of a bona fide target gene.

The identification of $\mathrm{mim}-1$ as a Myb-regulated gene raised several questions. For example, although c-myb is expressed in different types of hematopoietic and lymphoid cells, and transfection of mature myeloid cells with c-my $b$ induced $m i m-1$ gene expression, mim-1 mRNA was only detectable in promyelocytes [immature neutrophil granulocytes), a small subset of the cell types that express Myb (Queva et al. 1992). This suggested that 
another, unidentified cell type-specific factor might be required together with Myb to activate mim-1 expression, and perhaps other myeloid-specific genes as well. One candidate transcription factor that could play such a role is NF-M, which was first identified because it activates the expression of the gene encoding $\mathrm{CMGF}$, a chicken myelomonocytic-cell-specific cytokine (Sterneck et al., 1992). NF-M is a member of the CCAAT/ enhancer-binding protein (C/EBP) family and probably represents the chicken homolog of C/EBP $\beta$ (Sterneck et al. 1992; Katz et al. 1993).

The C/EBP-like transcription factors are a family of so-called bZip proteins, characterized by a basic DNAbinding region that is linked to a leucine zipper dimerization motif. The family contains three closely related members that include $\mathrm{C} / \mathrm{EBP} \alpha, \mathrm{C} / \mathrm{EBP} \beta$ /also called NFIL6, LAP, IL6-DBP, AGP/EBP, and CRP2), and C/EBP $\delta$ (CRP3, CELF; Landschulz et al. 1988; Birkenmeier et al. 1989; Akira et al. 1990; Chang et al. 1990; Descombes et al. 1990; Poli et al. 1990; Kageyama et al. 1991; Williams et al. 1991). The proteins have overlapping but distinct temporal patterns of expression during adipogenesis and myelomonocytic differentiation (Cao et al. 1991; Scott et al. 1992), and they form homo- or heterodimeric DNAbinding complexes that recognize similar regulatory elements in a sequence-specific manner. In an analogous fashion to c-Myb, C/EBP $\alpha$ and C/EBP $\beta$ are capable of regulating genes in different cell types, such as albumin in the liver and $422 \mathrm{aP} 2$ in adipocytes (Lichtensteiner et al. 1987; Cheneval et al. 1991). This tissue specificity is thought to result from combinatorial interactions with unrelated transcription factors bound to adjacent stretches of DNA (Descombes et al. 1990; Lamb and McKnight 1991).

Here, we describe that the induction of the mim-1 promoter not only requires the binding of Myb but also of NF-M. We also show that ectopic expression of NF-M in nonmyeloid cells allows Myb to activate both the mim-1 and lysozyme genes in inappropriate cell types. Our results demonstrate a cooperation between NF-M and Myb, implicating them as a bipartite "molecular switch" that determines the differentiation fate of myeloid cells.

\section{Results}

The mim-1 promoter binds tissue-specific factors in addition to $M y b$

The mim-1 gene was originally identified as a v-Mybregulated gene. In spite of this, it was only found to be expressed in a subset of $\mathrm{v}$-Myb-expressing cells (Ness et al. 1989). This suggested that tissue-specific factors cooperate with $\mathrm{Myb}$ to activate the gene. A mutational analysis of the mim-1 promoter was therefore performed to identify potential binding sites for myeloid-specific transcription factors. The first mutations made were in the Myb-binding sites, designated as the $\mathrm{A}, \mathrm{B}$, and $\mathrm{C}$ boxes, that are centered 145, 184, and 206 nucleotides upstream of the start site of mim-1 transcription, respectively. In each case, site-directed mutagenesis was used to invert two nucleotides so that the TAAC core was changed to TACA. Mobility-shift assays and DNase I footprinting experiments confirmed that the altered promoters were unable to bind bacterially expressed Myb proteins (data not shown). A number of $5^{\prime}$-end deletion mutants were also made, resulting in test constructs containing progressively shorter and shorter upstream sequences. All promoter constructs were reintroduced into a luciferase reporter gene plasmid, and their activities were tested in transient cotransfection assays.

As shown in Figure 1, the point mutations affecting the A box, the highest affinity Myb-binding site, blocked the ability of Myb to activate the promoter, resulting in a construct with very little residual activity. In contrast, disrupting the lower affinity $\mathrm{B}$ and $\mathrm{C}$ boxes, either individually (not shown) or in combination, had no effect on the activity of the promoter (Fig. 1). Similarly, deletions extending up to position -175 , which removed both the $\mathrm{C}$ and $\mathrm{B}$ boxes, had no detrimental effect on the promoter. This indicates that, at least in the context of these mim-1 promoter-reporter gene constructs, only the high-affinity A-box site is necessary for Myb inducibility and that multiple Myb-binding sites are not required to render the mim-1 promoter activatable by Myb. It also suggests that no sequences upstream of position -175 are required for the type of promoter activity detected in these cotransfection experiments. In contrast, deletions extending beyond position -161 , in the region between the A and B boxes, eliminated mim-1 promoter activity. DNA-binding experiments indicated that the -161 deletion did not affect the ability of bacterially expressed $\mathrm{Myb}$ protein to bind the promoter at the A-box site (not shown), ruling out the trivial explanation that those sequences might be required for $\mathrm{Myb}$ binding and suggesting that another, as yet unidentified,

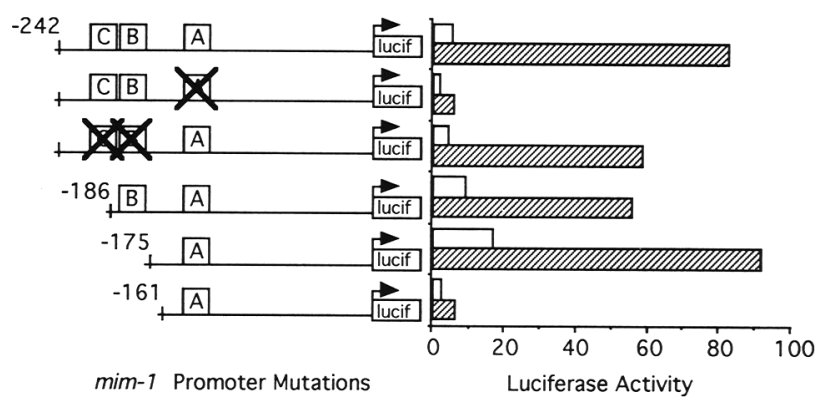

Figure 1. Mutational analysis of the mim-1 promoter. Wildtype and mutated forms of the mim-1 promoter-reporter gene constructs, diagramed at left, were transfected into HD11 macrophages either alone (open bars) or in combination with an E26 $\mathrm{v}$-Myb expression vector (hatched bars). The histogram at right shows the mean luciferase activity (duplicate assays), normalized for $\beta$-galactosidase expression from a cotransfected internal control plasmid. The promoter fragment extends from the HindIII site at position -242 to the Xhol site in the first intron, where it is fused to the luciferase reporter gene (lucif). The Mybbinding boxes are lettered $\mathrm{A}, \mathrm{B}$ and $\mathrm{C}$. Point mutations that block Myb binding and 5 '-end deletions are indicated by crosses and numbers, respectively. 
essential protein binds in the region adjacent to the $A$ box.

\section{$N F-M$ binds adjacent to $M y b$ on the mim-1 promoter}

The mutational analysis indicated that a tissue-specific protein binds the mim-1 promoter between positions -175 and -155 (the distal side of the $\mathrm{A}$ box). This was particularly interesting because the sequence contained a potential binding site for chicken NF-M /Sterneck et al. 1992), a transcription factor that probably represents the chicken version of $C / E B P \beta$. NF-M was first identified as a regulator of the $\mathrm{CMGF}$ gene, which encodes a myeloidspecific cytokine required for the growth of $\mathrm{v}$ - $m y b$-transformed cells, which, in turn, is expressed in the same cells as mim-1 (Sterneck et al. 1992). The cMGF promoter contains two NF-M-binding sites, both of which are required for myelomonocyte-specific activity (Sterneck et al. 1992). Because other proteins in the C/EBP family are known to be involved in tissue-specific gene regulation (Poli et al. 1990; Umek et al. 1991), NF-M seemed a good candidate for the myeloid-specific protein implicated in mim-1 activation. We therefore examined the mim-1 promoter for potential NF-M-binding sites by DNase I footprinting and mobility-shift assays.

NF-M protein was synthesized in bacteria, partially purified (Katz et al. 1993), and used for DNase I footprinting assays, which identified two binding sites for recombinant NF-M in the mim-1 promoter (data not shown). Both footprints overlapped regions of the promoter containing the sequence TT $x x$ CCAAC. The first footprint, at about position -60 , was near the location of a CCAAT-like sequence. The second footprint, centered on position -160 , was directly upstream of the A box, the high affinity Myb-binding site, in the region of the promoter found to be important for activation by the deletion analysis described above. We used a mobilityshift assay to determine whether the NF-M-binding sites (BS60 and BS160) in the mim-1 promoter could form a complex with myeloid cell-specific proteins. For this purpose, radiolabeled, double-stranded BS60 and BS160 oligonucleotides were incubated with nuclear extracts prepared from various cell types. As shown in Figure 2, proteins from the myeloid cells (HD11 macrophages and E26-transformed myeloblasts), both of which express NF-M, bound to the oligonucleotide probes and formed specific, slower migrating complexes. No such complexes were formed by extracts derived from cells that do not express NF-M, such as the lymphoid cell lines RPL12 and MSB-1, or the myeloid/erythroid progenitor cell line HD57 (Figure 2; Katz et al. 1993), suggesting that NF-M was the tissue-specific protein that bound to those sites.

These results were confirmed using mobility-shift assays with nuclear extracts of COS cells expressing recombinant NF-M and with nuclear extracts from HDl1 macrophages. As shown in Figure 3A, the control COS cell extracts (vector only) contained proteins that bound the mim-1-promoter probes, but the NF-M-expressing cells produced additional proteins that bound to both

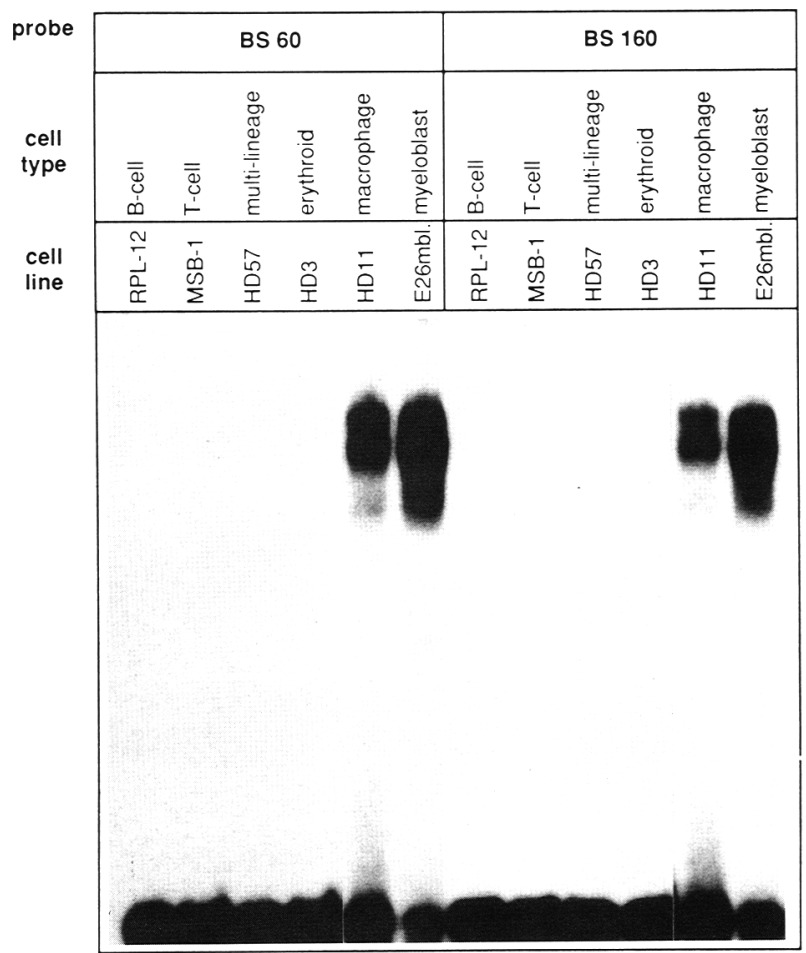

Figure 2. Myeloid cell-specific proteins bind to two sites in the mim-1 promoter. Nuclear extracts from various cell lines (indicated at $t o p$ / were incubated with radiolabeled, double-stranded oligonucleotide probes derived from the -60 and -160 regions of the mim-1 promoter (BS60 and BS160, respectively). The resulting complexes were visualized in a mobility-shift assay.

probes. These slower migrating complexes could be competed away with an excess of the same, unlabeled oligonucleotide but not with unrelated oligonucleotides, such as one derived from the Myb-binding A box. Finally, the addition of rabbit antiserum specific for chicken NF-M resulted in an even larger DNA/NF-M-antibody complex (a "supershift"), whereas the preimmune serum had no effect, proving that the slower migrating complexes contained the NF-M protein. Mobility-shift assays were also used to prove that the complexes formed by myeloid cell extracts contained NF-M. As shown in Figure 3B, very similar DNA-protein complexes formed when nuclear extracts from HD11 macrophages were incubated with radioactively labeled BS60 and BS160 oligonucleotides or with an oligonucleotide containing a previously characterized binding site for C/EBP $\alpha$. The addition of excess, unlabeled A-box oligonucleotide did not interfere with formation of the complexes, although they were completely abolished by the addition of excess oligonucleotide containing the C/EBP-binding site. All the complexes reacted with anti-NF-M antiserum, but not with preimmune serum, indicating that they contained native NF-M proteins. The fact that the NF-M antiserum was able to react with all of the complexes suggests either that NF-M is the only myeloid protein that is able to bind these C/EBP-like binding sites or that all such sites 

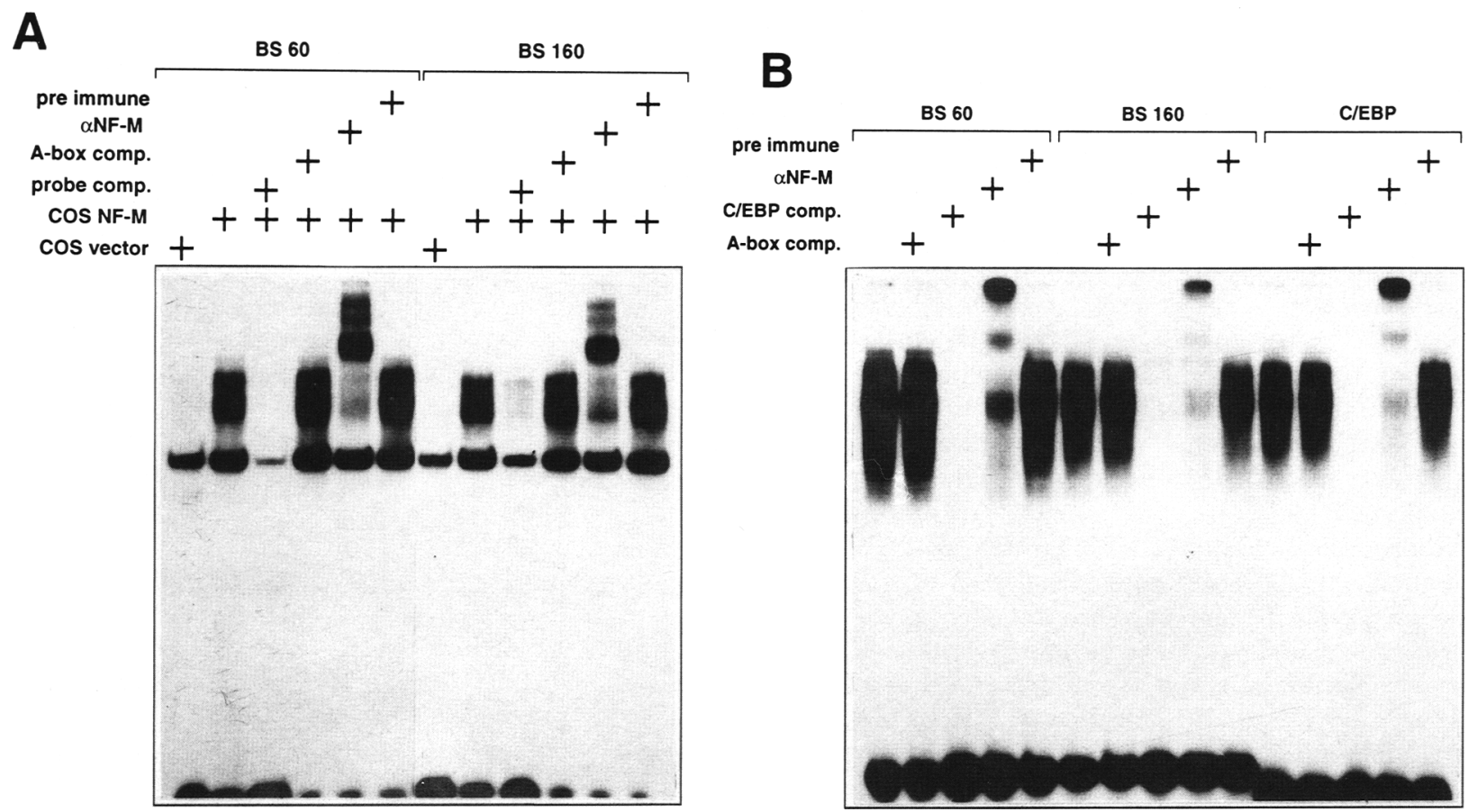

Figure 3. NF-M binds the mim-1 promoter. $(A)$ Nuclear extracts prepared from COS-7 cells transfected with a plasmid expressing chick NF-M (COS-NF-M) or with a control plasmid (COS vector) were incubated with radiolabeled, double-stranded oligonucleotides BS60, or BS160, and the resulting complexes were analyzed in a mobility-shift assay. Where indicated, a 200-fold excess of unlabeled BS60 or BS160 probe oligonucleotides (probe comp.) or Myb-binding A-box oligonucleotides (A-box comp.) were added to the binding reactions, as were either preimmune or anti-NF-M antiserum $(\alpha$ NF-M). The unbound probe runs at the bottom of the gel. $(B)$ Nuclear extracts prepared from HD-11 macrophages were incubated with various radiolabeled, double-stranded oligonucleotide probes, and the resulting complexes were visualized in a mobility-shift assay. Preimmune serum, NF-M-specific antiserum ( $\alpha$ NF-M), or an excess of Myb-binding A-box or C/EBP-binding oligonucleotides were added to the binding reactions where indicated.

are bound by protein complexes that contain NF-M. We conclude that the myeloid cell-specific protein NF-M binds to the mim-1 promoter at two sites, one of which, centered on position -160 , is directly adjacent to the high-affinity-binding site for Myb.

\section{NF-M cooperates with $M y b$ to activate the mim-1 promoter}

The DNA-binding assays described above suggested a role for NF-M in the myeloid-specific activity of the mim-1 promoter. We therefore used site-directed mutagenesis to disrupt the NF-M-binding sites in the mim-1 promoter-reporter constructs and tested the effects of the mutations in cotransfection assays using HD11 macrophages. As shown in Figure 4A, mutation of either the -160 or the -60 NF-M-binding site greatly reduced promoter activation by Myb, suggesting that both NF-Mbinding sites are required for full promoter activity. Figure $4 \mathrm{~B}$ shows that the mim-1 promoter is activated by Myb in HD11 cells, which already express NF-M but that expression is highest when both Myb- and NF-Mexpressing plasmids are introduced into the cells. This is presumably because the additional NF-M is able to overcome some negative regulatory mechanisms that are active in these cells (Katz et al. 1993).
We then analyzed how a dominant-negative mutant of NF-M, 5D229, would affect the activity of the mim-1 promoter in cells expressing NF-M. 5D229 has an aminoterminal deletion that removes the trans-activation domain, leaving the DNA-binding and dimerization motifs intact. Its dominant-negative behavior is attributed to its ability to form stable, DNA-binding dimers that are unable to activate transcription (Katz et al. 1993). As shown in Figure 4B, when 5D229 was transfected into HD11 cells, it not only failed to cooperate with Myb to activate transcription but actually inhibited the ability of Myb to activate the mim-1 promoter. Figure $4 \mathrm{C}$ shows that neither the truncated nor the full-length form of NF-M had any effect on the ability of Myb to activate a heterologous herpes simplex virus-thymidine kinase (HSV-TK) promoter linked to three synthetic A-box-like Myb-binding sites. This rules out the possibility that the dominant-negative 5D229 form of NF-M works by inhibiting the ability of Myb to bind to DNA or that it in some way inhibits the expression of Myb protein from the vector used in the cotransfection assays. Instead, our data suggest that 5D229 blocks the expression of mim-1 by interfering with the ability of NF-M to activate transcription, either by competing for binding sites on the mim-1 promoter or perhaps by forming inactive heterodimers with the full-length protein. We conclude that the bind- 

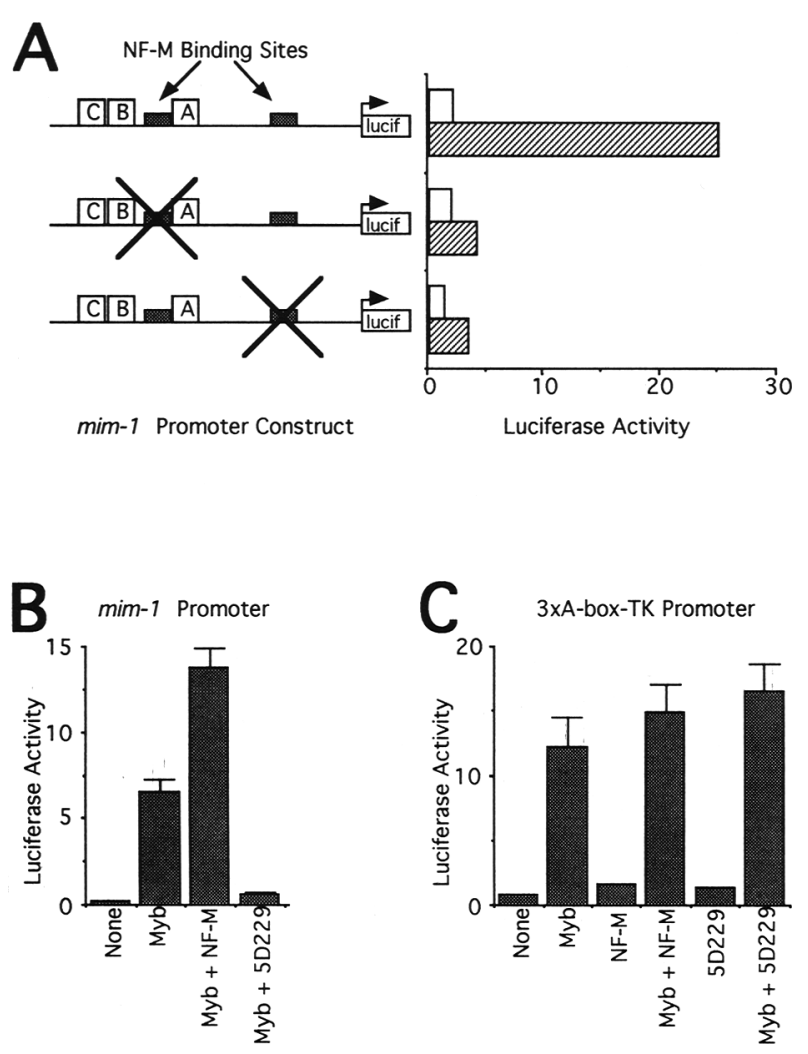

Figure 4. Myb and NF-M cooperate to activate the mim-1 promoter. Wild-type or mutated forms of the mim-1 promoterreporter gene constructs were transfected into HDll macrophage cells along with plasmids expressing the indicated transcription factors. The histograms show the average (triplicate assays) luciferase reporter gene activities, normalized for transfection efficiency. (A) NF-M-binding sites are required for mim-1 promoter activity. The relevant features of the wild-type and mutant mim-1 promoter constructs are diagramed at left. NF-M-binding sites are indicated by shaded boxes; inactivating point mutations by crosses. The Myb-binding sites are indicated by lettered boxes. The constructs were transfected alone lopen bars\} or in combination with an E26 Gag-Myb-Ets expression plasmid (hatched bars . (B) Activation of the mim-1 promoter by Myb plus NF-M. The wild type mim-1 promoter-reporter construct was transfected by itself (none) or with the indicated plasmids expressing E26 Gag-Myb-Ets (Myb) and either the fulllength (NF-M) or the dominant-negative deletion mutant (5D229) of NF-M. The values are the means of triplicate, normalized assays. Error bars indicate 1 s.CT. (C) Activation of a heterologous promoter. A test plasmid composed of three synthetic Myb-binding A-box site oligonucleotides introduced upstream of a minimal promoter from the HSV-TK gene-reporter construct was cotransfected with various activator plasmids as indicated and as described in $B$.

ing of both Myb and NF-M is required for efficient expression of the mim-1 promoter in myeloid cells.

\section{NF-M plus Myb activates the endogenous mim-1 gene in nonmyeloid cells}

The cotransfection assays demonstrated that the combination of Myb plus NF-M could induce the mim-1 pro- moter-reporter constructs. However, the induction of such constructs does not always parallel the activity of the endogenous mim-1 gene (Ness et al. 1989; Introna et al. 1990). So, the more significant question was whether either of the two transcription factors or their combination could induce the expression of the resident gene and whether this was also possible in nonmyeloid cells. We showed previously that the endogenous mim-1 gene could be activated in HDll macrophages transfected with v-myb-or c-myb-expressing plasmids (Ness et al. 1989; Queva et al. 1992). The Northern blots shown in Figure 5A confirm this and demonstrate that mim-1 activation is specific for $\mathrm{Myb}$, as transfection with NF-M or AP-1 (fos plus jun) expression vectors does not induce the gene. Coexpression of Myb and 5D229 (lanes 6), the dominant-negative mutant of NF-M, partially suppresses the activation of mim-1, presumably by interfering with the endogenously expressed NF-M in those cells.

A similar experiment was performed to see whether
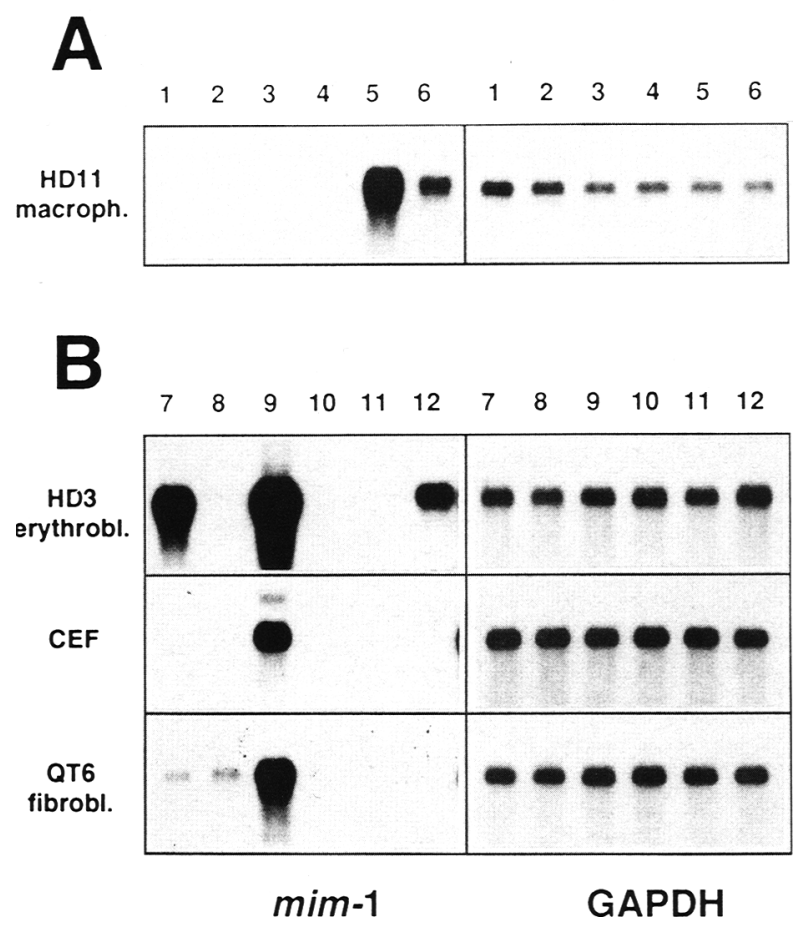

Figure 5. The combination of Myb plus NF-M induces mim-1 expression in nonmyeloid cells. Shown is a Northern blot analysis of Poly $(\mathrm{A})^{+}$RNAs prepared $36 \mathrm{hr}$ after transfection of various expression plasmids into different cell lines. The left and right panels show the same blots, sequentially hybridized with radiolabeled probes specific for mim-1 and GAPDH, respectively. $(A)$ HDll macrophages were transfected with plasmids expressing the following proteins: (Lanes 1), vector (pCDM8) only control; (Lanes 2) AP-1; (Lanes 3) 5D229/the dominantnegative deletion mutant of NF-M); (Lanes 4) wild-type NF-M; (Lanes 5) v-Myb (E26 virus Gag-Myb-Ets); (Lanes 6) v-myb plus 5D229. (B) The indicated nonmyeloid cells were transfected with plasmids expressing the following proteins: (Lanes 7) NF-

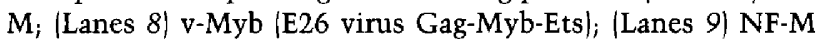
plus v-Myb; (Lanes 10) control vector DNA (pCDM8); (Lanes 11) AP-1; (Lanes 12) AP-1 plus NF-M. 
the mim-1 gene could be induced in nonmyeloid cells. We started with the immature erythroid cell line HD3, which expresses high endogenous levels of $c-m y b$ mRNA and protein but does not express NF-M or the mim-1 gene (Ness et al. 1989 and unpubl.). As shown in Figure 5B, transfection of HD3 cells with the NF-M expression vector alone (lanes 7) led to activation of the endogenous mim-1 gene, although the introduction of control DNAs or plasmids expressing AP-1 had no effect (lanes 10-11). This suggests that the ectopically expressed NF-M cooperated with c-myb protein to activate the gene. Interestingly, when plasmids expressing v-myb and NF-M were introduced simultaneously (lanes 9), the mim-1 gene was turned on to approximately threefold higher levels than with NF-M alone, suggesting that the endogenous levels of c-Myb protein in HD3 cells are limiting or that a functional difference between $\mathrm{v}-\mathrm{Myb}$ and c-Myb makes the former protein more active in this assay.

A Northern blot assay was also used to test whether the combination of Myb plus NF-M could activate the mim-1 gene in nonhematopoietic cells. The Myb and NF-M expression plasmids were transfected into primary chick embryo fibroblasts (CEFs) or the transformed quail fibroblast cell line QT6 (Moscovici et al. 1977), both of which are negative for $\mathrm{c}-\mathrm{Myb}$ and NF-M expression. As shown in Figure 5B, neither cell type expressed mim-1 before transfection or when the NF-M or Myb expression plasmids were introduced individually (lanes 7,8$)$. As before, transfection of control DNAs or an AP-1-expressing plasmid had no effect on mim-1 expression (lanes 10, 11). However, each time that Myb and NF-M expression vectors were introduced simultaneously, the endogenous mim-1 gene was induced to high levels (lane 9). Thus, the combinatorial action of Myb plus NF-M was sufficient to induce the expression of the endogenous mim-1 gene in every cell type tested, including cells as diverse as erythroid cells and fibroblasts.

\section{Other C/EBP-like proteins can also cooperate with $M y b$}

The previous analyses suggested that Myb and NF-M might constitute a bipartite signal for myeloid gene activation. The generality of this signal was examined by testing whether other types of C/EBP and/or Myb proteins could cooperate to activate the mim-1 gene and whether the lysozyme gene, which is known to be expressed in myeloid cells (Introna et al. 1990; Burk and Klempnauer 1991), might also be induced by the same combination of Myb plus NF-M. Primary cultures of CEFs were transfected with various combinations of plasmids encoding E26 virus v-myb (Gag-Myb-Ets), $\mathrm{c}-\mathrm{myb}$, NF-M, or $\mathrm{C} / \mathrm{EBP} \alpha$. As shown in Figure $6 \mathrm{~A}$, the mim-1 gene was induced efficiently in the fibroblasts transfected with any combination of plasmids expressing NF-M or rat C/EBP $\alpha$ plus either form of $M y b$, indicating that both C/EBP-like proteins can cooperate with Myb (lanes 6-9). In contrast, none of the plasmids induced significant mim-1 expression when transfected singly,

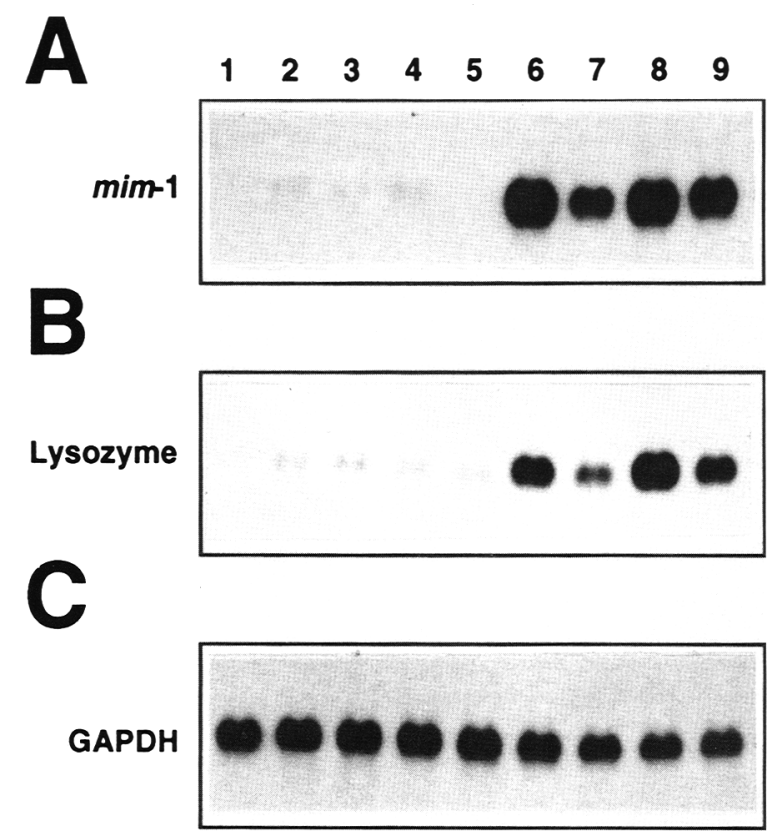

Figure 6. Myb and C/EBP-like proteins form a bipartite signal. Northern blot analysis of transfected CEFs was performed as described in the legend to Fig. 5. (Lane 1) Vector control; (Lane 2) NF-M alone; (Lane 3) C/EBPa (rat) alone; (Lane 4) v-Myb (E26 Gag-Myb-Ets) alone; (Lane 5) c-Myb alone; (Lane 6) NF-M + vMyb; (Lane 7) NF-M + c-Myb; (Lane 8) C/EBP $\alpha+\mathrm{v}-\mathrm{Myb}$; (Lane $9 \mid \mathrm{C} / \mathrm{EBP} \alpha+\mathrm{c}-\mathrm{Myb} . A-C$ show sequential hybridizations of the same blot with probes specific for mim-1, lysozyme, and GAPDH, respectively.

although some very weak, near background-level expression was observed in some experiments (lanes 2-5). The same Northern blot was rehybridized with a lysozymespecific probe. Figure 6B shows that lysozyme gene expression was also induced by a combination of $\mathrm{Myb}$ and $\mathrm{C} / \mathrm{EBP}$ proteins, suggesting that the combination of $\mathrm{Myb}$ plus C/EBP may induce a number of myeloid genes besides mim-1. Interestingly, $\mathrm{v}-\mathrm{Myb}$ in combination with either NF-M or C/EBP $\alpha$ was a more potent inducer than $\mathrm{c}-\mathrm{Myb}$. Whether this represents an intrinsic difference between $\mathrm{v}-\mathrm{Myb}$ and $\mathrm{c}-\mathrm{Myb}$, whether it reflects the fact that v-Myb is fused to v-Ets, or whether it is simply the result of differences in expression levels remains to be tested. Thus, ectopic expression of the transcription factors Myb and NF-M or Myb and C/EBP $\alpha$ was sufficient to induce the expression of both the mim-1 and lysozyme genes in heterologous cells. We conclude that Myb and NF-M constitute a bipartite, combinatorial signal that activates the expression of myeloid genes like mim-1 and lysozyme, even in the inappropriate cell type.

\section{Discussion}

In this paper we have described a combinatorial system of tissue-specific gene activation that is capable of inducing the expression of a myeloid cell-specific gene, mim-1, even in heterologous cell types. The signal is composed of two transcription factors, $c-m y b$ (or v-myb) 
and NF-M (C/EBP $\beta$ ), each of which is expressed in a particular tissue-specific pattern. The only cells that normally express both proteins are promyelocytes, the precursors of heterophils (chicken neutrophil granulocytes). They are also the only cells that express the mim-1 gene. We found that the mim-1 promoter binds both factors and that ectopic expression of Myb and NF-M in nonmyeloid cells results in activation of the resident mim-1 gene in such cells. This indicates that the combination of Myb with NF-M serves as a signal for the induction of myeloid-specific gene expression, much as MyoD1 and myogenin induce muscle-specific genes in nonmuscle cells (Davis et al. 1987; Wright et al. 1989).

\section{Mechanism of cooperation between Myb and NF-M}

Point mutations that disrupt the binding of either Myb or NF-M greatly impair the activity of the mim-1 promoter, indicating that both must bind to induce full activity. This suggests that the two factors act directly to activate mim-1 expression. The situation is less clear for the lysozyme gene because its promoter is not known to contain Myb-binding sites or to be regulated by Myb. However, an important distal regulatory region, the $-6.1-\mathrm{kb}$ enhancer, which has been shown to confer cell type specificity to the lysozyme gene /Grewal et al. 1992), does contain at least one binding site for NF-M (E. Kowenz-Leutz and A. Leutz, unpubl.|. It is therefore intriguing that lysozyme expression should be induced by the Myb/NF-M combination, because it may imply that the two transcription factors are able to induce heterologous cells to undergo a more general switch to the myeloid differentiation pathway. The lysozyme gene might be induced as an indirect result of such a switch.

The Myb and NF-M proteins bind the mim-1 promoter at adjacent sites, leading us to speculate that they might form a stable complex in solution. Such a possibility is supported by the finding that the second repeat of the DNA-binding domain of Myb, a helix-turn-helix motif (Frampton et al. 1989,1991), contains a potential protein-protein interaction site. This site was defined by mutations, present exclusively in the Myb protein encoded by AMV, which have no effect on its ability to bind DNA, but nevertheless eliminate the ability of the protein to activate mim-1 (Ness et al. 1989; Introna et al. $1990 \mid$. So far, attempts to demonstrate a direct interaction between Myb and NF-M have been unsuccessful (E. Kowenz-Leutz, A. Leutz, and S. Ness, unpubl.\}, although we cannot rule out the possibility that the proteins might interact via one or more bridging factors that are missing from our assays. In any case, it seems likely that Myb and NF-M must bind in close apposition to ensure that a functional connection is established with the basic transcription machinery. Further experiments should help distinguish between these alternatives.

\section{Molecular controls of myeloid differentiation and transformation}

We have suggested that the combination of Myb plus NF-M constitutes a combinatorial signal for myeloid gene expression. Although only two genes have been shown to be induced by this combination so far, it is likely that more will be found very soon. Our experiments have relied on Northern blots of transiently transfected fibroblasts and erythroid cells. The inefficiencies involved in such transfections make this a rather insensitive method and limit its usefulness to genes that are expressed abundantly, such as $\mathrm{mim}-1$ and lysozyme. The development of stable cell lines with regulatable versions of Myb and NF-M should lead to the isolation of more genes that are regulated in this way. Like lysozyme, many of these genes may be regulated only indirectly by Myb, which may only be required for the onset of the myeloid differentiation pathway. For example, the cMGF gene is regulated by a combination of NF-M and an AP-1-like factor (Sterneck et al. 1992), and we have recently observed that two other myeloid-specific genes can be activated in fibroblasts by transfection with NF-M only (E. Kowenz-Leutz and A. Leutz, unpubl.). Certainly, other types of transcription factors, such as retinoic acid receptor- $\alpha$ (Tsai et al. 1992), also play an important role in the lineage determination of myelomonocytic cells.

The observation that $c-m y b$ is essential for erythroid (Mucenski et al. 1991) and probably lymphoid cell growth and differentiation suggests that it also participates in the regulation of nonmyeloid genes. Do lymphoid- and erythroid-specific, perhaps NF-M-related proteins, cooperate with Myb to activate tissue-specific genes in those cell types? Mobility-shift assays have failed to detect NF-M-like DNA-binding proteins in lymphoid or erythroid cells (Haas et al. 1992; Sterneck et al. 1992), and C/EBP isoforms have been identified in myelomonocytic but not in other hematopoietic cells (Scott et al. 1992). This suggests that the myelomonocytic cells may be the only ones that express Myb and C/EBP-like proteins simultaneously. Thus, if Myb cooperates with tissue-specific factors in nonmyeloid cells, it seems likely that they will be unrelated to NF-M.

The induction of myeloid gene expression in nonmyeloid cell types has been described previously. Several laboratories have reported that a combination of activated forms of the raf and myc oncogenes can induce mouse $B$ cells to become macrophage-like (Klinken et al., 1988). This switch results in the expression of numerous myeloid-specific genes in cells that have retained rearranged immunoglobulin genes characteristic of B cells. However, the switch occurs only at low frequency, making analysis of the early events extremely difficult. It is relevant to point out that in $\mathrm{v}$-myc-transformed chick macrophages the expression of v-mil (the chicken homolog of $r a f \mid$ leads to induction of the NF-M-regulated cMGF gene (Adkins et al. 1984, Katz et al. 1993). Thus, it will be interesting to test whether kinase oncogenes like $\mathrm{raf} / \mathrm{mil}$ activate, in some way, the expression or the activity of NF-M and, if so, whether the introduction of NF-M into B cells might induce them to acquire myelomonocytic properties.

A final question raised by our studies is whether the target genes critical for cell transformation by v-myb are 
also under the control of NF-M. The v-myb oncogenes are somewhat unique in that they exclusively transform hematopoietic cells. Myb, itself, only transforms myeloid cells efficiently (Nunn and Hunter 1989; Introna et al. 1990; Metz and Graf 1991), although it can transform erythroid cells and more immature progenitor cells when coexpressed or complexed with the v-ets oncogene, as is the case with the E26 virus. The fact that $\mathrm{v}-$ my $b$ only transforms the cells that express NF-M suggests that the latter protein may be critically involved in the growth control of these cells. One way to directly test the involvement of NF-M in cell transformation induced by $\mathrm{v}-m y b$ is to determine the effects of the dominant-negative NF-M construct (or antisense oligonucleotides) on the growth of E26 or AMV-transformed myeloid cells. However, because NF-M expression is likely to be essential for a number of basic functions in myeloid cells, this experiment might be difficult to interpret. An alternative approach is to determine whether $\mathrm{v}-\mathrm{myb}$ would transform nontarget cells, such as fibroblasts, provided that these are cotransfected with NF-M. Such experiments, which are currently in progress, might ultimately help in elucidating the mechanism of myeloidspecific cell transformation and leukemogenesis.

\section{Materials and methods}

\section{Cells, media, and culture conditions}

The quail fibroblast cell line QT6 and the chicken cell lines HD3 (immature erythroid), HD11 (macrophages), and HD57 (myeloid/erythroid progenitors) have been described (Moscovici et al. 1977; Beug et al. 1979; Adkins et al. 1985; Graf et al. 1992). MSB-1 and RPL-12 are chicken T- and B-lymphoid cell lines, respectively (Beug et al. 1979). NIH-3T3 cells were obtained from R. Müller (Institut für Molekularbiologie and Tumorforschung, Marburg, Germany|. Primary E26 virus-transformed myeloblasts were derived from infected bone marrow cells as described previously (Beug et al. 1981; Ness et al. 1989). All were grown in Dulbecco's modified Eagle medium supplemented with $8 \%$ fetal bovine serum, $2 \%$ heat-inactivated chicken se rum, $10 \mathrm{~mm}$ HEPES-NaOH (pH 7.2), plus penicillin, and streptomycin (all from GIBCO/BRL). Primary myeloid cell cultures were supplemented with $20 \mathrm{U} / \mathrm{ml}$ of recombinant $\mathrm{CMGF}$ (Leutz et al. 1989) or concanavalin A-stimulated chicken spleen cell supernatant as a source of the same (Leutz et al. 1984). Avian and mouse cells were maintained in $5 \% \mathrm{CO}_{2}$ at $39^{\circ} \mathrm{C}$ and $37^{\circ} \mathrm{C}$, respectively.

\section{Transient transfections and promoter activation assays}

DNA transfections using DEAE-dextran, preparation of cell extracts, and reporter gene assays were all performed as described previously (Ness et al. 1989; Sterneck et al. 1992). COS-7 cells were transfected either with lipofectin (BRL) according to the manufacturer's instructions or with DEAE-dextran (Levesque et al. 1991). The mim-1 promoter-luciferase reporter gene constructs and the Myb expression vectors have been described (Ness et al. 1989; Introna et al. 1990). The cytomegalovirus (CMV) promoter-NF-M expression vectors were prepared by transferring an NF-M CDNA into the PCDM8 expression vector, as described elsewhere (Katz et al. 1993). Luciferase assays were performed using a Biolumat 9501 luminometer from Berthold. Results are reported as luciferase activity normalized either for an internal ( $\beta$-galactosidase) control of transfection efficiency or for milligrams of extract protein assayed. For Northern blot analysis, RNAs were prepared $30-36 \mathrm{hr}$ after transfection, either with a guanidinium- $\mathrm{HCl}$ method (Chomczynski and Sacchi 1987) or by SDS/proteinase-K treatment /Vennström and Bishop 1982). Poly $(A)^{+}$RNAs were prepared by oligo(dT)-cellulose chromatography (Aviv and Leder 1972; Vennström and Bishop 1982).

\section{PCR mutagenesis}

Point mutations in the mim-1 promoter were made by polymerase chain reaction (PCR)-mediated site-directed mutagenesis, by modifying published procedures (Higuchi et al. 1988). For deletion mutants, the $5^{\prime}$-most amplimer contained extra nucleotides, resulting in a product with an additional BamHI site added. In each case, the final products were digested with the appropriate restriction enzymes (usually BamHI and XhoI), purified by agarose gel electrophoresis, and recloned into the luciferase expression vector pXP2 (Nordeen 1988). The authenticity of each recombinant was confirmed by DNA sequencing and by DNase I footprint analysis using bacterially expressed $\mathrm{Myb}$ protein (Ness et al. 1989; Lim et al. 1992).

\section{Recombinant transcription factors}

The construction and characterization of the NF-M expression vectors are described in detail elsewhere (Katz et al. 1993). Briefly, the NF-M cDNA clone was transferred to the pATH2 vector, and expression of the resulting trpE-NF-M fusion protein was induced by tryptophan starvation. The recombinant NF-M was recovered from inclusion bodies by extraction with urea (Desplan et al. 1985). For expression in animal cells, an NF-M cDNA with an optimized eukaryotic translation initiation site (Kozak 1984) was transferred to the pCDM8 expression vector (Invitrogen), which has a CMV promoter (Seed 1987). The 5D229 dominant-negative version was made in the same way, except the $5^{\prime}$ end of the cDNA encoding the first 226 amino acids was also removed. The AP-1 expression plasmid encodes the chick v-jun and c-fos cDNAs (Sterneck et al. 1992).

\section{Synthetic oligonucleotides}

The following synthetic oligonucleotides were used to introduce mutations into the mim-1 promoter-luciferase constructs (mismatched nucleotides are underlined): AM, 5'-CTAAAAAACCTGTATAATGT-3' (A box); BM, 5'-TAAGACACCCTGTACTTTAC-3' (B box); CM, 5'-ATTTCCATCTTGTAATGTGA-3' (C box); M59, 5'-ACTGATTGGCGACCACAACAGTCCCA-3' (-60 site); Ml62, 5'-TCTTTCCCACACAGCTCTAAAAAACCG-3' |- 160 site).

The following oligonucleotide pairs were used to make double-stranded probes for mobility-shift experiments (nucleotides added for labeling purposes are in small type):

$$
\begin{aligned}
& \text { A box (coding) 5't } \mathrm{cg} \text { a gCTAAAAAACCGTTATAATGT } \mathrm{g}-3^{\prime}
\end{aligned}
$$

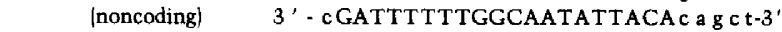

$$
\begin{aligned}
& \text { BS60 |codingl } 5^{\prime}-t \mathrm{c} \text { gAGGACTGATTGGCCAACACAACAG - } 3 \text { ' }
\end{aligned}
$$

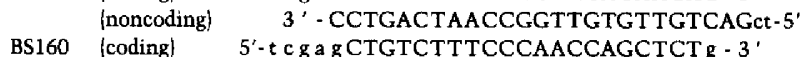

$$
\begin{aligned}
& \text { BS160 (coding) 5' t } \mathrm{cg} \text { a g CTGTCTTTCCCAACCAGCTCT } \mathrm{g}-3^{\prime} \\
& \text { C/EBP (coding) 5'-AATTCAATTGGGCAATCAGG-3' } \\
& \text { (noncoding) } \quad 3 \text { '- GTTAACCCGTTAGTCCTTAA - } 3
\end{aligned}
$$

\section{DNA-binding assays}

Nuclear extracts from hematopoietic cells or COS-7 cells were prepared as described (Sterneck et al. 1992) or by a mini-nuclear 
extract procedure (Schreiber et al. 1989). Double-stranded oligonucleotide probes were labeled with $\left[\alpha{ }^{32} \mathrm{P}\right] \mathrm{dCTP}$ by end-filling with Klenow polymerase. Mobility shifts were performed exactly as described previously (Sterneck et al. 1992). Where indicated, preimmune or polyclonal rabbit antisera raised against bacterially expressed chicken NF-M protein /Katz et al. 1993) was diluted 1/600 with PBS and added to the binding reaction $15 \mathrm{~min}$ after mixing the nuclear extract and DNA. The samples were incubated for an additional $10 \mathrm{~min}$ on ice before electrophoresis.

\section{RNA analysis}

Total RNA was extracted using guanidinium isothiocyanate |Chomczynski and Sacchi 1987), and the poly $\left(\left.\mathrm{A}\right|^{+}\right.$fraction was isolated by oligo(dT)-cellulose chromatography (Aviv and Leder 1972). RNAs were fractionated on $1 \%$ formaldehyde-agarose gels, transferred to Hybond membranes (Amersham), UV crosslinked, and baked at $80^{\circ} \mathrm{C}$ for $2 \mathrm{hr}$. The restriction fragments used as probes for GAPDH, mim-1, and lysozyme have been described (Dugaiczyk et al. 1983; Stueber et al. 1984; Ness et al. 1989 ) and were labeled by random priming (Stratagene kit). Hybridization was performed using QuikHyb (Stratagene) at $65^{\circ} \mathrm{C}$ for $2 \mathrm{hr}$. Subsequently, the filters were washed twice with $0.2 \times$ SSC, $0.1 \%$ SDS, at $60^{\circ} \mathrm{C}$ and exposed to Kodak XAR5 X-ray film. Filters were rehybridized after stripping for $30 \mathrm{~min}$ at $55^{\circ} \mathrm{C}$ in $50 \%$ formamide, $0.1 \%$ SDS, $0.1 \times$ SSC.

\section{Acknowledgments}

We thank Åsa Marknell, Julie Kaplan-Arey, and Yi Shen for outstanding technical assistance, Joe Lipsick, Steven McKnight, R. Umek, Sylvia Katz, and Christine Müller for providing materials and plasmids, Jon Frampton for discussions, and Angela Wandinger-Ness for comments on the manuscript. S.A.N. was supported in part by a grant from the Leukemia Research Foundation, Inc. E.K.-L. and A.L. were supported by grants from the Deutsche Forschungsgemeinschaft (SFB229) and from the Bundesministerium für Forschung und Technologie (BMFT).

The publication costs of this article were defrayed in part by payment of page charges. This article must therefore be hereby marked "advertisement" in accordance with 18 USC section 1734 solely to indicate this fact.

\section{References}

Adkins, B., A. Leutz and T. Graf. 1984. Autocrine growth induced by src-related oncogenes in transformed chicken myeloid cells. Cell 39: 439-445.

- 1985. Viral oncogenes of the src gene family induce growth factor production and stimulate transformed chicken myeloblasts to proliferate in an autocrine fashion. Cancer Cells 3: 87-93.

Akira, S., H. Ishiki, T. Sugita, O. Tanabe, S. Kinoshita, Y. Nishio, T. Nakajima, T. Hirano, and T. Kishimoto. 1990. A nuclear factor for IL-6 expression. NF-IL6 is a member of a C/EBP family. EMBO I. 9: 1897.

Aviv, H. and P. Leder. 1972. Purification of biologically active globin messenger RNA by chromatography on oligothymidylic acid-cellulose. J. Mol. Biol. 134: 743.

Beug, H., A. Von Kirchbach, G. Döderlein, J.F. Conscience, and T. Graf. 1979. Chicken hematopoietic cells transformed by seven strains of defective avian leukemia viruses display three distinct phenotypes of differentiation. Cell 18: 375390.
Beug, H., H. Müller, S. Grieser, G. Döderlein, and T. Graf. 1981. Hematopoietic cells transformed in vitro by REV-T avian reticuloendotheliosis virus express characteristics of very immature lymphoid cells. Virology 115: 295-309.

Beug, H., A. Leutz, P. Kahn, and T. Graf. 1984. Ts mutants of E26 leukemia virus allow transformed myeloblasts, but not erythroblasts or fibroblasts, to differentiate at the nonpermissive temperature. Cell 39: 579-588.

Biedenkapp, H., U. Borgmeyer, A.E. Sippel, and K.H. Klempnauer. 1988. Viral myb oncogene encodes a sequence-specific DNA-binding activity. Nature 335: 835-837.

Birkenmeier, E.H., B. Gwynn, S. Howard, J. Jerry, J.I. Gordon, W.H. Landchulz, and S.L. McKnight. 1989. Tissue-specific expression, developmental regulation, and genetic mapping of the gene encoding CCAAT/enhancer binding protein. Genes \& Dev. 3: 1146-1156.

Boyle, W.J., M.A. Lampert, J.S. Lipsick, and M.A. Baluda. 1984. Avian myeloblastosis virus and E26 virus oncogene products are nuclear proteins. Proc. Natl. Acad. Sci. 81: 4265-4269.

Burk, O. and K.-H. Klempnauer. 1991. Estrogen-dependent alterations in differentiation state of myeloid cells caused by a $\mathrm{v}-\mathrm{myb} / \mathrm{estrogen}$ receptor fusion protein. EMBO $/$. 10: 37133719.

Cao, Z., R.M. Umek, and S.L. McKnight. 1991. Regulated expression of three C/EBP isoforms during adipose conversion of 3T3-L1 cells. Genes \& Dev. 5: 1538-1552.

Chang, C.-J., T.-T. Chen, H.-Y. Lei, D.-S. Chen, and S.-C. Lee. 1990. Molecular cloning of a transcription factor, AGP/EBP, that belongs to the C/EBP family. Mol. Cell. Biol. 10: 66426653.

Cheneval, D., R.J. Christy, D. Geiman, P. Cornelius, and M.D. Lane. 1991. Cell-free transcription directed by the 422 adipose P2 gene promoter: Activation by the CCAAT/enhancer binding protein. Proc. Natl. Acad. Sci. 88: 8465-8469.

Chomczynski, P. and N. Sacchi. 1987. Single-step method of RNA isolation by acid guanidinium thiocyanate-phenolchloroform extraction. Anal. Biochem. 162: 156-159.

Clarke, M.F., J.F. Kukowska-Latallo, E. Westin, M. Smith, and E.V. Prochownik. 1988. Constitutive expression of a c-myb cDNA blocks friend $\mathrm{ml}$ :ine erythroleukemia cell differentiation. MoI. Cell. Biol. 8: 884-892.

Davis, R.L., H. Weintraub, and A.B. Lassar. 1987. Expression of a single transfected cDNA converts fibroblasts to myoblasts. Cell 51: 987-100.

Descombes, P., M. Choikier, S. Lichtensteiner, E. Falvey, and U. Schibler. 1990. LAP, a novel member of the C/EBP gene family, encodes a liver-enriched transcriptional activator protein. Genes \& Dev. 4: 1541-1551.

Desplan, C., J. Theis, and P.H. O'Farrell. 1985. The Drosophila developmental gene, engrailed, encodes a sequence-specific DNA binding activity. Nature 318: 630-635.

Dugaiczyk, A., J.A. Haron, E.M. Stone, O.E. Dennison, K.N. Rothblum, and R.J. Schwartz. 1983. Cloning and sequencing of a deoxyribonucleic acid copy of glyceraldehyde-3-phosphate dehydrogenase messenger ribonucleic acid from chicken muscle. Biochemistry 22: 1605-1613.

Duprey, S.P. and D. Boettiger. 1985. Developmental regulation of c-myb in normal myeloid progenitor cells. Proc. NatI. Acad. Sci. 82: 6937-6941.

Frampton, J, A. Leutz, T. Gibson, and T. Graf. 1989. DNA binding domain ancestry. Nature 342: 134.

Frampton, J., T.J. Gibson, S.A. Ness, G. Döderlein, and T. Graf. 1991. Proposed structure for the DNA-binding domain of the Myb oncoprotein based on model building and mutational analysis. Prot. Eng. 4: 891-901.

Gabrielsen, O.S., A. Sentenac, and P. Fromageot. 1991. Specific 
DNA binding by c-Myb: Evidence for a double helix-turnhelix-related motif. Science 253: 1140-1143.

Gewirtz, A.M. and B. Calabretta. 1988. A c-myb antisense oligodeoxynucleotide inhibits normal human hematopoiesis in vitro. Science 242: 1303-1306.

Gewirtz, A.M., G. Anfossi, D. Venturelli, S. Valpreda, R. Sims, and B. Calabretta. 1989. Gl/S transition in normal human T-lymphocytes requires the nuclear protein encoded by c-myb. Science 245: 180-183.

Gonda, T.J., D.K. Sheiness, and J.M. Bishop. 1982. Transcripts from the cellular homologs of retroviral oncogenes: Distribution among chicken tissues. Mol. Cell. Biol. 2: 617-624.

Graf, T. 1992. Myb: A transcriptional activator linking proliferation and differentiation in hematopoietic cells. Curr. Opin. Gen. Dev. 2: 249-255.

Graf, T., K. McNagny, G. Brady, and J. Frampton. 1992. Chicken erythroid cells transformed by the Gag-Myb-Ets-encoding E26 leukemia virus are multipotent. Cell 70: 201-213.

Grewal, T., M. Theisen, U. Borgmeyer, T. Grussenmeyer, R.A.W. Rupp, A. Stief, F. Qian, A. Hecht, and A.E. Sippel. 1992. The -6.1-kilobase chicken lysozyme enhancer is a multifactorial complex containing several cell-type-specific elements. Mol. Cell. Biol. 12: 2339-2350.

Haas, J.G., M. Ströbel, A. Leutz, P. Wendelgass, C. Müller, E. Sterneck, G. Riethmüller and H.W.L. Ziegler-Heitbrock. 1992. Constitutive monocyte-restricted activity of NF-M, a nuclear factor that binds to a C/EBP motif. I. Immunol. 149: 237-243.

Higuchi, R., B. Krummel, and R.K. Saiki. 1988. A general method of in vitro preparation and specific mutagenesis of DNA fragments: Study of protein and DNA interactions. Nucleic Acids Res. 16: 7351-7367.

Ibanez, C.E. and J.S. Lipsick. 1990. trans activation of gene expression by v-myb. Mol. Cell. Biol. 10: 2285-2293.

Introna, M., J. Golay, J. Frampton, T. Nakano, S.A. Ness, and T. Graf. 1990. Mutations in v-myb alter the differentiation of myelomonocytic cells transformed by the oncogene. Cell 63: 1287-1297.

Kageyama, R., Y. Sasai, and S. Nakanishi. 1991. Molecular characterization of transcription factors that bind to the cAMP responsive region of the substance $\mathrm{P}$ precursor gene. J. Biol. Chem. 226: 15525-15531.

Kalkbrenner, F., S. Guehmann, and K. Moelling. 1990. Transcriptional activation by human $\mathrm{c}$-myb and $\mathrm{v}$-myb genes. Oncogene 5: 657-661.

Kanei-Ishii, C., A. Sarai, T. Sawazaki, H. Nakagoshi, D.-N. He, K. Ogata, Y. Nishimura, and S. Ishii. 1990. The tryptophan cluster: A hypothetical structure of the DNA-binding domain of the myb protooncogene product. I. Biol. Chem. 265: 19990-19995.

Kastan, M.B., K.D. Stone, and C.I. Civin. 1989. Nuclear oncoprotein expression as a function of lineage, differentiation stage and proliferative status of normal human hematopoietic cells. Blood 74: 1517-1524.

Katz, S., E. Kowenz-Leutz, C. Müller, K. Meese, S.A. Ness, and A. Leutz. 1993. The NF-M transcription factor is related to $\mathrm{C} / \mathrm{EBP} \beta$ and plays a role in signal transduction, differentiation and leukemogenesis of avian myelomonocytic cells. $E M B O$ /. 12: 1321-1332

Katzen, A.L., T.B. Kornberg, and J.M. Bishop. 1985. Isolation of the proto-oncogene c-myb from D. melanogaster. Cell 41: 449-456.

Klempnauer, K.-H., G. Symonds, G.I. Evans, and J.M. Bishop. 1984. Subcellular localization of proteins encoded by oncogenes of avian myeloblastosis virus and avian leukemia virus E26 and by the chicken c-myb gene. Cell 37: 537-547.
Klinken, S.P., W.S. Alexander, and J.M. Adams. 1988. Hemopoietic lineage switch: v-raf oncogene converts $E m \mu$-myc transgenic B cells into macrophages. Cell 53: 857-867.

Kozak, M. 1984. Compilation and analysis of sequences upstream from the translational start site in eukaryotic $\mathrm{mR}$ NAs. Nucleic Acids Res. 12: 857-872.

Lamb, P. and S.L. McKnight. 1991. Diversity and specificity in transcriptional regulation: The benefits of heterotypic dimerization. Trends Biochem. Sci. 16: 417-422.

Landschulz, W.H., P.F. Johnson, E.Y. Adashi, B.J. Graves, and S.L. McKnight. 1988. Isolation of a recombinant copy of the gene encoding C/EBP. Genes \& Dev. 2: 786-800.

Leutz, A., H. Beug, and T. Graf. 1984. Purification and characterization of CMGF, a novel chicken myelomonocytic growth factor. EMBO I. 3: 3191-3197.

Leutz, A., K. Damm., E. Sterneck, E. Kowenz, S. Ness, R. Frank, H. Gausepohl, A.-C.E. Pan, J. Smart, M.J. Hayman, and T. Graf. 1989. Molecular cloning of the chicken myelomonocytic growth factor. cMGF reveals relationship to interleukin 6 and granulocyte colony stimulating factor. $E M B O \%$ 8: $175-181$.

Levesque, J.P., P. Sansilvestri, A. Hatzfeld, and J. Hatzfeld. 1991. DNA transfection in COS cells: A low-cost serum-free method compared to lipofection. BioTechniques 11:313314.

Lichtensteiner, S., J. Wuarin, and U. Schibler. 1987. The interplay of DNA-binding proteins on the promoter of the mouse albumin gene. Cell 51: 963-1073.

Lim, F., N. Kraut, J. Framptom, and T. Graf. 1992. DNA binding by c-Ets-1, but not v-Ets, is repressed by an intramolecular mechanism. EMBO I. 11: 643-652.

Lüscher, B. and R.N. Eisenman. 1990. New light on Myc and Myb. Part II. Myb. Genes \& Dev. 4: 2235-2241.

McClinton, D., J. Stafford, L. Brents, T.P. Bender, and W.M. Kuehl. 1990. Differentiation of mouse erythroleukemia cells is blocked by late up-regulation of a c-myb transgene. Mol. Cell. Biol. 10: 705-710.

Metz, T. and T. Graf. 1991. v-myb and v-ets transform chicken erythroid cells and cooperate both in trans and in cis to induce distinct differentiation phenotypes. Genes \& Dev. 5: 369-380.

Moscovici, C., M.G. Moscovici, H. Jiminez, M.M.C. Lai, M.J. Hayman, and P.K. Vogt. 1977. Continuous tissue culture cell lines derived from chemically induced tumors of Japanese quail. Cell 11: 95-103.

Mucenski, M.L., K. McLain, A.B. Kier, S.H. Swerdlow, C.M. Schreiner, T.A. Miller, D.W. Pietryga, J.W.J. Scott, and S.S. Potter. 1991. A functional c-myb gene is required for normal murine fetal hepatic hematopoiesis. Cell 65: 677-689.

Nakagoshi, H., T. Nagase, C. Kanei-Ishii, Y. Ueno, and S. Ishii. 1990. Binding of the c-myb proto-oncogene product to the simian virus 40 enhancer stimulates transcription. J. Biol. Chem. 265: 3479-3483.

Ness, S.A., $\AA$. Marknell, and T. Graf. 1989. The v-myb oncogene product binds to and activates the promyelocyte-specific mim-1 gene. Cell 59: 1115-1125.

Nishina, Y., H. Nakagoshi, F. Imamoto, T.J. Gonda, and S. Ishii. 1989. Trans-activation by the c-myb proto-oncogene. Nucleic Acids Res. 17: 107-117.

Nordeen, S.K. 1988. Luciferase reporter gene vectors for analysis of promoters and enhancers. BioTechniques 6: 454-457.

Nunn, M.F. and T. Hunter. 1989. The ets sequence is required for induction of erythroblastosis in chickens by avian retrovinus E26. I. Virol. 63: 398-402.

Paz-Ares, J., D. Ghosal, U. Wienand, P.A. Peterson, and H. Saedler. 1987. The regulatory cI locus of Zea mays encodes a 
protein with homology to myb proto-oncogene products and with structural similarities to transcriptional activators. EMBO I. 6: 3553-3558.

Poli, V., F.P. Mancini, and R. Cortese. 1990. IL-6DBP, a nuclear protein involved in interleukin- 6 signal transduction, defines a new family of leucine zipper proteins related to C/EBP. Cell 63: 643-653.

Queva, C., S.A. Ness, F.A. Grässer, T. Graf, B. Vandenbunder, and D. Stéhelin. 1992. Expression patterns of c-myb and of $\mathrm{v}$-myb induced myeloid. mim-1 gene during the development of the chick embryo. Development 114: 125-133.

Saikumar, P., R. Murali, and E.P. Reddy. 1990. Role of tryptophan repeats and flanking amino acids in Myb-DNA interactions. Proc. Natl. Acad. Sci. 87: 8452-8456.

Schreiber, E., P. Matthias, M.M. Muller, and W. Schaffner. 1989. Rapid detection of octamer binding proteins with "mini-extracts", prepared from a small number of cells. Nucleic Acids Res. 17: 6419.

Scott, L.M., C.I. Civin, P. Rorth, and A.D. Friedman. 1992. A novel temporal expression pattern of three C/EBP family members in differentiating myelomonocytic cells. Blood 80: $1725-1735$.

Seed, B. 1987. An LFA-3 cDNA encodes a phospholipid-linked membrane protein homologous to its receptor CD2. Nature 329: 840-842.

Sterneck, E., C. Müller, S. Katz, and A. Leutz. 1992. Autocrine growth induced by kinase-type oncogenes in myeloid cells requires AP-1 and NF-M, a myeloid-specific, C/EBP-like factor. $E M B O$ \% 11: 115-126.

Stueber, D., I. Ibrahimi, D. Cutler, B. Dobberstein, and H. Bujard. 1984. A novel in vitro transcription-translation system: Accurate and efficient synthesis of single proteins from cloned DNA sequences. EMBO 1. 3: 3143-3148.

Tice-Baldwin, K., G.R. Fink, and K.T. Arndt. 1989. BASI has a myb motif and activates HIS4 transcription only in combination with BAS2. Science 246: 931-935.

Todokoro, K., R.J. Watson, H. Higo, H. Amanuma, S. Kuramochi, H. Yanagisawa, and Y. Ikawa. 1988. Down-regulation of c-myb gene expression is a prerequisite for erythropoietin induced erythroid differentiation. Proc. Natl. Acad. Sci. 85: 8900-8904.

Tsai, S., S. Bartelmez, R. Heyman, K. Damm, R. Evans, and S.J. Collins. 1992. A mutated retinoic acid receptor- $\alpha$ exhibiting dominant-negative activity alters the lineage development of a multipotent hematopoietic cell line. Genes \& Dev. 6: $2258-2269$.

Umek, R.M., A.D. Friedman, and S.L. McKnight. 1991. CCAAT-enhancer binding protein: A component of a differentiation switch. Science 251: 288-292.

Vennström, B. and J.M. Bishop. 1982. Isolation and characterization of chicken DNA homologous to the two putative oncogenes of avian erythroblastosis virus. Cell 28: 135-143.

Weston, K. and J.M. Bishop. 1989. Transcriptional activation by the v-myb oncogene and its cellular progenitor, c-myb. Cell 58: 85-93.

Williams, S.C., C.A. Cantwell, and P.F. Johnson. 1991. A family of C/EBP-related proteins capable of forming covalently linked leucine zipper dimers in vitro. Genes \& Dev. 5: 15531567.

Wright, W.E., D.A. Sassoon, and V.K. Lin. 1989. Myogenin, a factor regulating myogenesis, has a domain homologous to myoD. Cell 56: 607-617. 


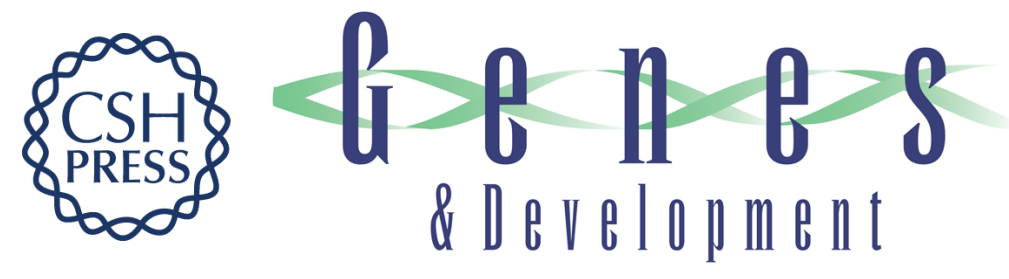

\section{Myb and NF-M: combinatorial activators of myeloid genes in heterologous cell types.}

S A Ness, E Kowenz-Leutz, T Casini, et al.

Genes Dev. 1993, 7:

Access the most recent version at doi:10.1101/gad.7.5.749

References This article cites 77 articles, 31 of which can be accessed free at:

http://genesdev.cshlp.org/content/7/5/749.full.html\#ref-list-1

License

Email Alerting

Service

Receive free email alerts when new articles cite this article - sign up in the box at the top right corner of the article or click here.

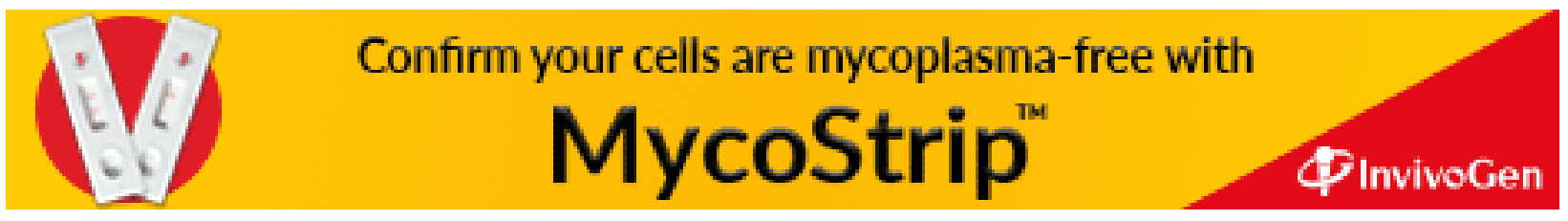

